\title{
Work as a Core Activity: Working Voluntarily in Kingdom Boys Football Academy from Republic of Ireland
}

\author{
${ }^{*}$ Cemal IYYEM, Fuat MAN \\ Sakarya University Business School, Turkey \\ *ciyem@sakarya.edu.tr
}

\begin{abstract}
The last half of the $20^{\text {th }}$ century witnessed so great debates in social sciences. Many scholars examined the transformation that occurred in industrialized society and tried to redefined it: some of them called the new form of this society as post-fordist society while some others called as postmodern, post industrialized, post bureaucratic and so on. All these attempts have tried to tell same thing: the society is no more the same industrial society. Every sample has affected from that transformation and of course 'works' itself.This study aims to examine the relation between work and leisure and discuss the place of voluntary work in that frame using a case from The Kingdom Boys Football Academy fromRepublic of Ireland.The methodology of the paper depends on two types. The first part of the paper will examine the literature of voluntary work. Thus, the methods of this part will be literature review. The main part of the paper, second part, will ground on 'the case'. The methods of the research will be participant observation.
\end{abstract}

Keywords: Work, Voluntary Work, Leisure

\section{Introduction and Literature Review}

Exploring the meaning of work is like walking on uncertain fields. The term 'work' recalls a set of concepts that have close meaning with it. The researchers in sociology of work have done numerous categories to clear the meaning of work. Work and leisure, paid work and unpaid work, formal and informal work, visible and hidden work etc. all these separations are attempts to simplify the meaning of work. Where should voluntary work be located in that frame? In addition, what is the relation between work, leisure and voluntary work? Noon and Blyton (2002) locate the voluntary work under the hidden work side in a visible-hidden scale. Noon and Blyton (2002) defines the hidden work as a productive activity but not figure in national accounts of production or earnings. They categorize the hidden works under two titles. One refers the activities that are 'concealed' because they are illegal, they are contain illegal aspects and attract social stigma, or because the income deriving from legal activities in not declared to the tax authorities. The other title for hidden works is 'unrecognised works' in that context. These activities are labelled as hidden because of not generally being performed for payment, thus placing those work activities not only outside market relations but also outside the range of activity widely considered to constitute 'real' work. Domestic work and voluntary work are placed under this title. This paper tries to explore voluntary work as a sub-title of hidden work with the connection of leisure time. Before depict this connection it will be more explanatory to overview on the voluntary work sector in England and Ireland. According to Citizenship Survey (2009), some facts about voluntary work in England are following:

In $2008 / 0971 \%$ of adults volunteered in some way with $47 \%$ volunteering at least once a month. In 2008/09 41\% of adults volunteered formally (giving unpaid help through a group, club or organisation) and $62 \%$ volunteered informally (giving unpaid help as an individual to someone who is not a relative). In $2007 / 08$, formal volunteers contributed an estimated $£ 22.7$ billion to the UK economy. The average number of hours spent volunteering per volunteer declined by 30\% between 1997 and 2007 (Helping Out, 2007). Evidence also suggests that there is a trend towards more episodic volunteering. What about the facts for Ireland? In 2006, responding organisations to the Hidden Landscape survey reported having a total 1,570,408 volunteers. Based on the 2006 census figures this represents $37.1 \%$ of the total population $(4,234,925)$ volunteer. In 2006 the reported time, 465,624 hours per year, was spent volunteering. Volunteers are more important in sports and recreation, environment, arts and culture and religious groups than in other ICNPO (The International Classification of Non-profits Organizations) categories. Volunteering rates are dependent, amongst other things, on age, sex, socio-economic status, marital status and where people live. Estimates on the in-kind revenue from volunteering in Ireland range from €200-600 million. Compared to other European countries, Ireland's volunteering rate is average and 
its citizens' membership of community and voluntary associations is above average; both rates are on the increase VI (2009).

All these figures show the size and importance voluntary sector. One figure from Ireland shows also another fact about the nature of voluntary work. That is the number of voluntaries that non-Ireland base. The number consists of almost nine per cent of voluntaries. This point is important for the fact that shows the relations between policy makers and this sector. Taylor (2005) states that 'successive governments have viewed voluntary work as a cost-effective weapon in the fight against particular social problems such as juvenile delinquency and unemployment.' This statement implies a clear connection between voluntary works and policy makers or state. This explanation contains also the central position of work for modern times. As it known, the perception toward work has shifted from labour as an activity of slaves in Ancient Greek Clair et al. (2008) to one of all citizens in modern era (Bauman 1998, Foucault 2005). Modern times have designed all institutions and perceptions to keep alive and survive capitalism. The great reason of changing in perception of labour has been that reality. This reality contains also great need to control all society. Thus working, no matter it is paid or unpaid, has become a core activity for all individuals in any society in capitalist formation. On the other hand, there are some other great transformations in the capitalist production mode that expands the size of voluntary work. One of these transformations is the reduction on working hours in Western European countries. The other one is labour migration to these countries (Boswell 2005). These both developments with some other facts have improved voluntary works sectors. Especially one kind of voluntary works is about the leisure. As stated above, volunteers are more important in sports and recreation, environment, arts and culture and religious groups.Examining the literature, there are three general perspectives on the relationship between work and leisure (Auster, 1996). The first one is spill over or holistic. This approach is an optimistic view that implies meaning and satisfaction are found in both work and leisure. The other one is pluralistic view that implies that there are a variety of ways in which both work and leisure can be satisfying. The last perspective is dualistic or compensatory perspective and this last one especially reflects partly the view of our paper. This perspective supports the idea that work and leisure are quite separate. This pessimistic view of work suggests that leisure activities are chosen to compensate for dissatisfaction with work. This paper examining the experiences of those who worked voluntarily in a soccer club and in that frame it is not difficult to make connection between voluntary works and leisure. The next part of the paper will examine these experiences closely.

\section{Methodology}

The study from which these accounts are drawn uses qualitative methods which is "participant observation" to capture working voluntarily in Kingdom Boys Football Academy from Republic of Ireland. Participant observation is a qualitative method with roots in traditional ethnographic research, whose objective is to help researchers learn the perspectives held by study populations. Participant observation always takes place in community settings, in locations believed to have some relevance to the research questions. Unlike the survey participant observation, the epistemology of the qualitative interview tends to be more constructionist than positivist. The primary aim of the participant observation was to investigate the incidence, nature of voluntary work.Finally,we used this method because we tried to learn what lifelooks like for an "insider".Furthermore, we have been 9 months to Ireland for some academic purposes under Erasmus Programme and when we have been Ireland, we worked voluntary in Kingdom Boys Football Academy. In this context, this study shows our voluntary work experience between September 2008 and May 2009 at Kingdom Boys Football Academy in Ireland.

Limitations of Study:The case of Kingdom Boys Football Academy do not represent all voluntary work around the world. In this study, we just tried to explain voluntary work with the case of Kingdom Boys Football Academy from Republic of Ireland. We volunteered with the Kingdom Boys FC in Tralee / Ireland. The role within this volunteering included facilitating and planning training sessions for the under 7's, 9's and 10's teams. The club and its entire members were very helpful from the very beginning offering assistance whenever needed. A training course was provided for a number of coaches, as Kickstart 1, which is an official FAI training programme for soccer coaches. This programme is designed to take amateur coaches and train them so that they can become competent voluntary coaches for ages fewer thanseven's to under 10's. All trainings includes various types of games and activities that can be used in a session and also little tips and how to get groups attention and keep it, which the writers found to be very important due to the age group that these potential coaches were going to be training. 
Mission of the Club and Our Voluntary Work Experiences:The mission of the Kingdom Boys Football Club is to care for school boys/girls that are involved in the club by giving them an opportunity to participate in an outdoor activity, which allows them to develop their physical and mental growth. The club encourages friendship, character building and improving the children's self-confidence, while also cultivating their football skills to the best of their ability.Kingdom Boys FC is a relatively young club in comparison to the other sporting clubs in Ireland. It was formed in 1999 and since then has won a lot of respect from the other clubs and Irish society. Sessions are once a week for an hour and a half and at the moment they are 130 children assigned to the Academy (from under 7's to under 10's).We can see there are some very important points to this mission statement that will have positive benefits for those children taking part in the club. First of all it, allows the children a chance to participate in an outdoor activity that is fun and relatively safe. Furthermore, our participant observation show to us, obesity trends in Ireland are on the rise. Early intervention such as getting children active can help reduce the risk of possible health problems in their future, and therefore reduce the strain on our health services in the years to come.Secondly, we will say the club offers children a chance to develop physically and mentally. This is very important at an early age and it can help develop co-ordination a lot quicker, improving their fitness and their reflexes. In addition, their mental skills will develop as the child learns to think quickly when playing or training, allowing their decision-making abilities to improve with every practice session. Moreover, the club also says in Mission Statement that they encourage friendship and character building, along with a growth in that individual's confidence. Therefore, the club helps to develop a child's social skills, allowing them to make new friends outside of school or neighbourhood. There is a great sense of comradely when a person is part of a team, and for children this is very important as it makes it so much easier to make friends and grow as individuals. Therefore, we saw with our experiences that Kingdom Boys Football Club targets all the important aspects for development of the children ensuring their physical, mental and social growth are improved and worked on.

\section{Voluntary Work in Kingdom Boys Football Academy:}

Training:All prospective coaches must participate in a training programme, which qualifies them to coach soccer. This particular programme is the first in a series of add-on training programmes. The courser covers a wide range of topics such as ethics, appropriate group management skills and a number of games/activities that can be used when delivering a training session. Therefore, we can see very different type of voluntary work. This voluntary work has included a training programme, and you have to join this programme before voluntary work in Kingdom Boys Football Academy.

Induction:The induction into the club is quite simple. Anyone who is interested voluntary work can join this group. Induction can also happen to parents who drop their children to the sessions and if they are standing around watching, quite often, they will be asked to join in and give a helping hand at the sessions and their help is of great importance. This is how many coaches have begun training groups in the younger age groups.

Screening:Each volunteer fills out a form that contains his or her details such address, past experience with clubs, etc. and they must also include at least 2 references who are contacted and asked over the phone about individual.

Support:The club receives support from its volunteers mainly with minimal help coming from sponsors of any kind.

Motivation for Volunteers in Kingdom Boys F.C.:The biggest motivational factor for volunteers in the club is family. $65-70 \%$ of all volunteers have children involved in playing with the club. Most of these volunteers began because they used to come up and watch the session and so would be approached and asked if they would like to help out. This helps make the volunteers at the Kingdom Boys Football Club very dedicated and interested in the welfare of the club and its players.In addition, a love of the game is a big factor. Almost all the volunteers have played soccer in their lifetime and are appreciative of the fact that they had coaches who spent their time training them and now they want a chance to pass on that knowledge to the next generation. They feel they are giving something back into the community in which they live in. This can also been seen as in investment into the future of the community. Volunteers also have a number of difficulties to overcome. Initially when people are asked to come along and coach a team, they can often be afraid that they do not have the necessary skills to coach soccer. This can have a 
negative affect on a person's decision to join up because if he/she does not feel comfortable in this role then it is very unlikely they will join up as a coach.

\section{Conclusion}

To volunteer means simply, to be motivated and give one's time or energies to work towards a project or cause that you are interested in. Volunteering experience enables people to learn new skills and cultures, to develop and gain practical experience in the field in, sometimes demanding conditions, and to develop leadership and teamwork skills. Volunteering takes many forms and is performed by a wide range of people. Normally people work voluntary in their leisure time. Therefore, we can say voluntarily work involves a combination of work and leisure.In this context, this paper we tried to thinking on voluntary work and its relations with leisure. In fact, there are several aspects of voluntary works. Its history, its connections with church charity organisation, relations with welfare state, and connection with nation state or controlling society are very important aspects. However, the aim of this paper has been just to share some experiencing in voluntary works with the connection of leisure. However, saying a great origin for voluntary works for Western European countries, the capitalist production mode have a great effect on it. Although the first cases of voluntary activities arises from charity organisation, its history dates back to the era of industrial revolution. This implies a clear reality. That reality is the central position of working in the capitalist society. However, the structure of voluntary works shows us a positive conclusion. This kind of work push individuals to public sphere and this also make a great contribution to development of civil society.As this study has showed so many families, join some voluntary works for some purposes about their family. This motivation leads a vein to develop civil society. On the other hand, this kind of work of course has a connection with the capitalist formation. Because all these activities reproduce the formation and keep the members of society on an intended positions: keeping them far from crime, some health risks and producing 'solidarity' between the members of society that makes them a 'society'.

\section{References}

Auster, C. J. (1996). The Sociology of Work: Concepts and Cases, London: Pine Forge Press.

Bauman, Z. (1998). Work, Consumerism and the New Poor, Open University Press.

Boswell, C. (2005). Migration in Europe, Global Commission on International Migration.

Citizenship Survey (2009). Citizenship Survey: 2008-09 (April 2008 - March 2009),England, Cohesion Research Statistical Release 8, July 2009.

Clair, R. P., Megan, M., Stephanie, B., Kyle, H.\&Stephanie, M. (2008). Why Workthe Perception of a 'Real Job' and the Rhetoric of Work through the Ages, Indiana: Purdue University Press

Foucault, M. (2005). Madness and Civilization, London: Routledge

Taylor, R. F. (2005). Rethinking Voluntary Work, in 'A New Sociology of Work?' (Edts.) Lynne Pettinger, Jane Parrey, Rebecca Taylor and Miriam Glucksmann, 119-135, Oxford: Blackwell.

Noon, M.\&Blyton, P. (2002). The Realities of Work, NY: Palgrave

VI. (2009). Facts \& Figures, Voluntary Ireland, http://www.volunteeringireland.ie/page.php?id=11 accession date $21 / 05 / 2010$. 